$\begin{array}{lll}\text { Ali Mehdi, MD, MEd } & \text { Jonathan J. Taliercio, DO } & \text { Georges Nakhoul, MD, MEd } \\ \text { Department of Nephrology and Hypertension, } & \text { Medical Director, Cleveland Clinic West Dialysis } & \text { Director, Center for Chronic Kidney Disease, } \\ \text { Cleveland Clinic; Assistant Professor, } & \text { Unit, Department of Nephrology and Hypertension, } & \text { Department of Nephrology and Hypertension, } \\ \text { Cleveland Clinic Lerner College of Medicine of Case } & \text { Cleveland Clinic; Assistant Professor, Cleveland Clinic } & \text { Cleveland Clinic; Assistant Professor, Cleveland Clinic } \\ \text { Western Reserve University, Cleveland, OH } & \text { Lerner College of Medicine of Case Western Reserve } & \text { Lerner College of Medicine of Case Western Reserve } \\ & \text { University, Cleveland, OH } & \text { University, Cleveland, OH }\end{array}$

\title{
Contrast media in patients with kidney disease: An update
}

\section{ABSTRACT}

Concern for contrast-induced acute kidney injury (Cl-AKI) or nephrogenic systemic fibrosis may lead to withholding important studies from patients with kidney disease. However, the actual risk or even the existence of these conditions has recently been called into question. The truth probably lies somewhere in the middle.

\section{KEY POINTS}

The risk of $\mathrm{Cl}-\mathrm{AKI}$ appears to be highest in patients with the lowest kidney function, but the overall risk is lower than initially thought.

In the absence of an equivalent alternate study, iodinated contrast studies that are thought to be crucial to the care of patients with kidney disease should not be withheld out of concern for $\mathrm{Cl}-\mathrm{AKI}$.

Volume expansion with isotonic fluid appears to be the only intervention with a possible benefit in preventing $\mathrm{Cl}$-AKI. This is recommended in high-risk patients unless they are clinically volume-overloaded.

With the highly stable class II gadolinium-based contrast agents, the risk of nephrogenic systemic fibrosis appears to be extremely low and as such safe even for patients with advanced, predialysis kidney disease.

End-stage kidney disease patients on dialysis do require a hemodialysis treatment immediately after gadolinium administration.

The authors report no relevant financial relationships which, in the context of their contributions could be perceived as a potential conflict of interest.

doi:10.3949/ccjm.87a.20015
Contrast-Induced acute kidney injury (CI-AKI) and nephrogenic systemic fibrosis (NSF) have been 2 of the most feared adverse effects of iodinated contrast media for computed tomography (CT) and gadoliniumbased contrast media for magnetic resonance imaging (MRI), respectively. Newer and safer contrast agents and, perhaps, better patient selection and prophylactic measures have ameliorated those risks. Recently, some authors have suggested that NSF has been eradicated, while others question whether CI-AKI is an actual entity.

This review presents and evaluates the data around CI-AKI and NSF and critically highlights the most recent practice guidelines.

\section{IODINATED CONTRAST AND 'RENALISM'}

Iodinated contrast media are commonly used in modern medicine both intravenously with CT studies and arterially during angiographic procedures. Among the possible adverse effects is acute kidney injury, first reported in the 1950s in patients undergoing intravenous pyelography. ${ }^{1}$ In the 1980 s, larger series of cases of acute kidney injury following coronary angiography were reported, and the term contrast-induced nephropathy was coined. ${ }^{2}$ With growing attention, it was said to be one of the most common causes of hospital-acquired acute kidney injury, ${ }^{3}$ contributing significantly to incident chronic kidney disease, end-stage kidney disease, and death. ${ }^{4}$

Early publications defined contrast-induced nephropathy as an increase in creatinine of $0.5 \mathrm{mg} / \mathrm{dL}$ or more, or a $25 \%$ increase from baseline within 2 to 5 days of exposure.

In 2012, the Kidney Disease Improving Global Outcomes Working Group suggested 


\section{TABLE 1}

\section{Nomenclature and definitions of kidney injury related to iodinated contrast media}

Contrast-induced nephropathy-Traditional term for worsening kidney function within 48 hours of iodinated contrast media. This term has largely been replaced by contrast-induced acute kidney injury.

Contrast-associated acute kidney injury-Any acute kidney injury occurring within 48 hours of iodinated contrast media. The term implies correlative diagnosis and does not suggest a causal relationship between the acute kidney injury and the iodinated contrast media.

Postcontrast acute kidney injury—Synonymous with contrastassociated acute kidney injury. This term appears in the radiology literature. Similar to contrast-associated acute kidney injury, it implies correlative diagnosis without suggesting a causal relationship between the acute kidney injury and the iodinated contrast media

Contrast-induced acute kidney injury-Replaced contrastinduced nephropathy as the accepted terminology when acute kidney injury is causally linked to iodinated contrast media. It is a subset of contrast-associated acute kidney injury.

\section{Cl-AKI usually presents within 24 to 48 hours of exposure to iodinated contrast media}

the term CI-AKI and defined it as a $50 \%$ increase in creatinine from baseline within 7 days of exposure or a $0.3 \mathrm{mg} / \mathrm{dL}$ increase within 48 hours. ${ }^{5} \mathrm{CI}-\mathrm{AKI}$ is now the accepted terminology to describe kidney injury precipitated by iodinated contrast media.

\section{Presentation}

CI-AKI usually presents within 24 to 48 hours of exposure to iodinated contrast media, with elevation in creatinine and, rarely, oliguria. The creatinine level peaks by 3 to 5 days and usually returns to baseline by 7 to 10 days. Sediment analysis shows granular casts and tubular epithelial cells, and the fractional excretion of sodium is usually low.

Risk factors include chronic kidney disease, diabetes, proteinuria, volume depletion, and concomitant exposure to other nephrotoxins. Procedure-related factors include higher-osmolality contrast media, higher volume given, multiple administrations of iodinated contrast media, and intra-arterial administration with first-pass effect. ${ }^{2,6}$

The diagnosis is clinical, and it is prudent to rule out other causes of acute kidney injury, in particular, atheroembolic kidney disease in patients undergoing angiography with iodinated contrast media. ${ }^{7}$ While the true inci- dence of atheroembolic kidney disease compared with that of CI-AKI in this situation is not known, supporting evidence comes from reports demonstrating a correlation between the risk of acute kidney injury and atheroma burden, ${ }^{8}$ and a lower risk with radial than with femoral angiographic procedures. ${ }^{9}$ This disease has a very different clinical course but is commonly misdiagnosed as CI-AKI.

\section{Pathophysiologic basis}

The pathophysiologic basis for CI-AKI is still not completely understood, but direct and indirect mechanisms have been suggested. ${ }^{10}$

Iodinated contrast media are directly toxic to the tubular epithelial cells, leading to loss of polarity (loss of channel restriction to either luminal or basolateral membranes) and eventual apoptosis and necrosis. Elevated blood osmolality due to the contrast media, increased viscosity of the luminal fluid, and free radical formation have also been implicated in direct toxicity. 7,8

Deranged hemodynamics underlie the indirect adverse effects of iodinated contrast media, with a brief initial vasodilatory state followed by pronounced and sustained vasoconstriction. Prolonged vasoconstriction, which appears to be mediated through alterations in endothelin, nitric oxide, adenosine, and prostaglandin levels, eventually leads to medullary ischemia. Tubuloglomerular feedback has also been postulated as an explanation for the drop in glomerular filtration rate observed in CI-AKI.

\section{Is it all a myth?}

Over the past decade, a number of large epidemiologic studies suggested that acute kidney injury following exposure to iodinated contrast media is not necessarily caused by the contrast media. Some reports even questioned whether it is a real disease. ${ }^{11}$ This has sparked much debate and led to newer names for the phenomenon, including postcontrast acute kidney injury and contrast-associated acute kidney injury (Table 1 ). The rationale of these new definitions is to eliminate the causality associated with the term CI-AKI.

Whether one believes CI-AKI is real or a myth, this debate is not merely theoretical because conclusions drawn have significant implications for the care of our patients who have 
chronic kidney disease. For example, Chertow et $\mathrm{al}^{12}$ reported an inappropriately low rate of cardiac angiographic procedures in patients who have chronic kidney disease. Presumably, procedures were withheld out of concern for CI-AKI. They coined the term "renalism" to indicate the perhaps inappropriate attention to the kidneys while ignoring the bigger picture. Although it is not yet reported, one could presume the notion of avoidance may encompass all contrast-enhanced CT studies in the chronic kidney disease population.

Those who question the diagnosis of CIAKI point to studies reporting similar rates of acute kidney injury in patients undergoing contrast-enhanced CT compared with those undergoing an unenhanced study. Davenport et $\mathrm{al}^{13}$ used a $1: 1$ propensity matching algorithm and retrospectively reviewed over 17,000 patients who underwent contrast-enhanced CT or unenhanced CT. In patients whose estimated glomerular filtration rate (eGFR) was less than $30 \mathrm{~mL} / \mathrm{min} / 1.73 \mathrm{~m}^{2}$, the rate of acute kidney injury was significantly higher in those exposed to contrast $(36.4 \%$ vs $19.4 \%$, odds ratio $2.96,95 \%$ confidence interval 1.22-7.17). In those with eGFRs of 30 to $59 \mathrm{~mL} / \mathrm{min} / 1.73 \mathrm{~m}^{2}$ rates were numerically higher with contrast than without contrast, but the difference did not reach statistical significance, and rates were the same with or without contrast in those with eGFRs of 60 or higher.

McDonald et $\mathrm{al}^{14}$ and, more recently, Hinson et $\mathrm{al}^{15}$ performed similar large epidemiologic propensity-controlled studies showing no difference in rates of acute kidney injury between contrast recipients and those who underwent unenhanced CT. Notably, both studies demonstrated no difference regardless of the definition of acute kidney injury or eGFR stratification. However, patients with eGFRs less than $45 \mathrm{~mL} / \mathrm{min} / 1.73 \mathrm{~m}^{2}$ were significantly underrepresented in these studies, accounting for only $5 \%$ to $10 \%$ of participants, with some studies completely excluding patients whose creatinine was above $4 \mathrm{mg} / \mathrm{dL} .{ }^{15}$

Does that mean that CI-AKI does not exist? We believe that would be an erroneous conclusion. Despite the complex algorithms used in the propensity matching, a selection bias remains as to who undergoes contrast CT and who does not. Clinicians' perceptions of risks and consequently their decisions to give or withhold contrast cannot be ascertained from retrospective analyses. In addition, prevention strategies, or lack thereof, are not accounted for in these large database-driven studies. Moreover, as stated previously, patients with severely decreased eGFR, who are at highest risk of CI-AKI, were underrepresented in the propensity score studies.

However, the risks of CI-AKI are probably overstated. Initial descriptive studies were mostly uncontrolled, and rates of acute kidney injury were based mostly on ICD codes with little adjudication as to the cause. This would ultimately inflate the rates of acute kidney injury attributed to the iodinated contrast media. ${ }^{16,17}$ In addition, changing practices, such as prophylaxis, minimizing exposure, and the development of less toxic, lower-osmolar iodinated contrast media have probably played an important role in reducing the rates of CIAKI.

Nevertheless, CI-AKI remains real. A recent meta-analysis with more than 1,500 patients undergoing peripheral angiography found a higher incidence of acute kidney injury with iodinated contrast media than with carbon dioxide contrast ( $11 \%$ vs $4 \%$, respectively. ${ }^{18}$ In addition, our group recently published a propensity-matched study evaluating rates of acute kidney injury in patients with stage 3 or 4 chronic kidney disease undergoing coronary angiography, contrast-enhanced CT, or nonenhanced CT. ${ }^{19}$ Postcontrast acute kidney injury was noted in $27 \%, 24 \%$, and $24 \%$ of patients, respectively. All cases of acute kidney injury were then adjudicated by 2 nephrologists through chart review to ascertain the cause. They found that the incidence of CI-AKI was $16.5 \%$ in the coronary angiography group and $12.5 \%$ in the contrast-enhanced CT group.

Therefore, despite the lack of conclusive data, CI-AKI remains very much a real entity, although the incidence is lower than originally thought.

\section{The evidence, or lack of evidence, for preventive strategies}

The evidence regarding strategies to prevent CI-AKI is far from satisfying. Hiremath and 
Velez ${ }^{16}$ described it as "a proliferation of small, underpowered trials, often with interventions that were poorly thought out" and said that "subsequent meta-analyses have spawned meta-confusion." With that in mind, we will try to critically evaluate some of the proposed prophylactic interventions.

\section{Volume expansion}

Solomon et $\mathrm{al}^{20}$ first reported volume expansion with $0.45 \%$ saline to be effective in preventing CI-AKI. Mueller et $\mathrm{al},{ }^{21}$ analyzing 1,620 patients, reported a lower incidence of acute kidney injury with periprocedural use of isotonic saline than with $0.45 \%$ saline.

Although hydration has become the accepted standard, the recent AMACING trial challenged its role in preventing CI-AKI. Nijssen et $\mathrm{al}^{22}$ randomized 660 patients undergoing contrast-enhanced procedures to undergo volume expansion with $0.9 \%$ normal saline or no volume expansion. The latter was found to be noninferior to saline, but the overall rates were low. Notably, patients with an eGFR less than $30 \mathrm{~mL} / \mathrm{min} / 1.73 \mathrm{~m}^{2}$ were excluded from the study.

More recently, Timal et $\mathrm{al}^{23}$ performed a randomized multicenter trial in 523 patients with stage 3 chronic kidney disease undergoing contrast-enhanced CT. Randomization to no hydration was noninferior to prehydration with bicarbonate in terms of postcontrast acute kidney injury, with event rates of $2.7 \%$ vs $1.5 \%$ respectively (relative risk $1.7,95 \% \mathrm{CI}$ 0.5-5.9). Noninferiority was also shown on subgroup analyses based on age, eGFR (30-44 vs $45-60 \mathrm{~mL} / \mathrm{min} / 1.73 \mathrm{~m}^{2}$ ) alone or in combination with risk factors including diabetes. However, the event rate in this trial was lower than in previous trials, and therefore, caution should be used with interpreting the results.

The type of fluid used for volume expansion has also been a topic of debate, with bicarbonate-based hydration protocols proposed. The premise is that urinary alkalinization would ameliorate the direct toxicity of iodinated contrast media by decreasing oxygen free-radical generation. ${ }^{10}$

Multiple small trials and subsequent metaanalyses provided highly divergent results until the Prevention of Serious Adverse Events Following Angiography (PRESERVE) trial put this discussion to rest. ${ }^{24}$ This large 2-by2 factorial study randomly assigned 5,177 patients undergoing nonemergency angiography to receive isotonic sodium bicarbonate vs isotonic saline as well as oral acetylcysteine vs placebo. The trial was stopped early due to futility, with acute kidney injury rates of $9.5 \%$ in the bicarbonate group and $8.3 \%$ in the saline group $(P=.13)$. Therefore, there is no additional benefit to bicarbonate-based hydration compared with isotonic saline.

\section{Pharmacotherapy}

Acetylcysteine. The acetylcysteine story mirrors that of bicarbonate: a multitude of small studies followed by a series of meta-analyses yielding conflicting results. However, 2 studies over the past few years should settle this discussion for good: the Coronary and $\mathrm{Pe}$ ripheral Vascular Angiography (ACT) trial, ${ }^{25}$ with 2,308 patients undergoing an intravascular angiographic procedure randomized to acetylcysteine vs placebo, and the previously mentioned PRESERVE trial. ${ }^{24}$ Both trials showed no difference in rates of acute kidney injury between the acetylcysteine and placebo groups.

Statins have been postulated to reduce the risk of CI-AKI because of their pleiotropic anti-inflammatory and antioxidant effects, which help stabilize plaque. There have been many conflicting studies, with recent meta-analyses suggesting a possible benefit in patients undergoing coronary angiography. ${ }^{10}$ Whether this benefit is due to prevention of CI-AKI or atheroembolic kidney disease is not clear. Most patients who undergo coronary angiography ultimately receive high-dose statin therapy anyway, making this a moot point.

Other interventions, including vitamin $\mathrm{C}$, high-flow oxygen, and ischemic preconditioning are promising but the evidence remains lacking.

In summary, volume expansion with isotonic saline appears to be the only intervention with a possible benefit in preventing CIAKI. This is probably important in patients deemed to be at intermediate to high risk (Table 2). Acetylcysteine has no role as a prophylactic measure, and bicarbonate-based fluids do not appear to offer an added benefit beyond volume expansion. Other preventive measures 
TABLE 2

\section{lodinated contrast media in patients with kidney disease: Key points from the ACR-NKF consensus statement \\ Consensus statement \\ Authors' comments}

The risk of contrast-induced acute kidney injury is substantially less than the risk of contrast-associated acute kidney injury, but the actual risk remains uncertain. However, necessary contrast-enhanced CT without an alternative should not be withheld.

Patients at risk for contrast-induced acute kidney injury include those with recent acute kidney injury or those with eGFR $<30 \mathrm{~mL} / \mathrm{min} / 1.73 \mathrm{~m}^{2}$ (including nonanuric dialysis patients).

Prophylaxis with intravenous isotonic saline is indicated for patients with $\mathrm{eGFR}<30 \mathrm{~mL} / \mathrm{min} / 1.73 \mathrm{~m}^{2}$ not undergoing dialysis and in patients with acute kidney injury.

Prophylaxis should be individualized for high-risk patients with eGFR between 30 and $44 \mathrm{~mL} / \mathrm{min} / 1.73 \mathrm{~m}^{2}$.

Prophylaxis is not indicated for patients with stable eGFR $\geq$ $45 \mathrm{~mL} / \mathrm{min} / 1.73 \mathrm{~m}^{2}$.
We believe this statement should be extrapolated to patients in whom coronary angiographic procedures are deemed necessary.

Age, diabetes, hypertension, and proteinuria are absent from the risk classification. We believe patients with an eGFR $<45 \mathrm{~mL}$ $\mathrm{min} / 1.73 \mathrm{~m}^{2}$, particularly those with the above noted risk factors, should also be considered at increased risk.

We believe that prophylaxis is also warranted in nonanuric patients on hemodialysis or peritoneal dialysis to preserve residual kidney function. Careful attention to volume status is required to avoid hypervolemia.

We support prophylaxis in this population, particularly in the presence of traditional risk factors (diabetes, hypertension, proteinuria).

We concur that the risk of contrast-induced acute kidney injury in this population is low.

$\mathrm{ACR}=$ American College of Radiology; CT = computed tomography; eGFR = estimated glomerular filtration rate; NKF = National Kidney Foundation

include using low- or iso-osmolar contrast media with the lowest necessary total dose.

We also advocate withholding nonsteroidal anti-inflammatory drugs, diuretics, angiotensin-converting enzyme inhibitors, and angiotensin II receptor blockers in high-risk patients, acknowledging that the data in that regard are insufficient.

Figure 1 shows our approach when patients with chronic kidney disease require iodinated contrast media.

Note that we generally include nonanuric patients undergoing hemodialysis or peritoneal dialysis in our high-risk category, and unless they are clinically hypervolemic, we recommend prophylaxis to preserve residual kidney function. A reanalysis of the CanadaUSA (CANUSA) peritoneal dialysis study ${ }^{26}$ elegantly demonstrated that being able to produce as little as $250 \mathrm{~mL}$ of urine per day was associated with a $36 \%$ lower relative risk of death in peritoneal dialysis patients.

Although the data are less robust, this observation likely applies to hemodialysis patients as well, thus underscoring our recommendation for prophylaxis. ${ }^{27}$ We emphasize that the goal of hydration in this nonanuric dialysis population is not to make them hypervolemic, and as such, hydration should be forgone in overtly volume-overloaded patients.

The ideal hydration protocol for prevention remains uncertain, and various volumeexpansion algorithms have been suggested using fixed or weight-adjusted regimens. Our practice is to give 1 to $1.5 \mathrm{~mL}$ per kg per hour starting 1 hour before and continuing for 6 hours after exposure to iodinated contrast media.

\section{Updated recommendations}

In response to the changing evidence, the American College of Radiology and the National Kidney Foundation released a joint consensus statement this year ${ }^{28}$ on the use of intravenous iodinated contrast media in patients with kidney disease. Key points are presented in Table 2.
Volume expansion with isotonic saline appears to be the only intervention with a possible benefit in preventing Cl-AKI 
Authorities and radiology societies were quick to react to the crisis of gadoliniuminduced NSF

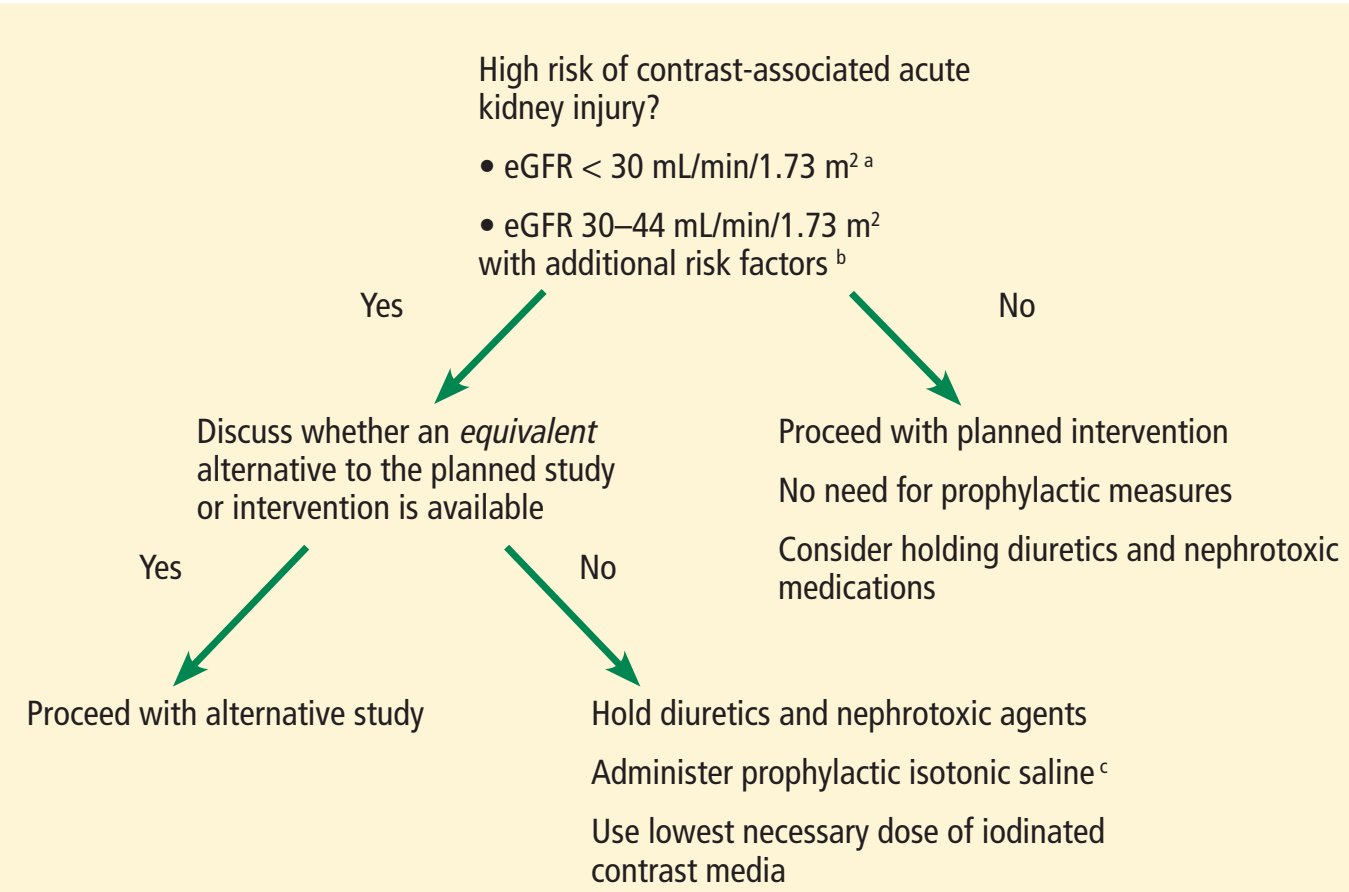

This includes hemodialysis and peritoneal dialysis patients with residual kidney function.

${ }^{b}$ Risk factors include age, diabetes, hypertension, volume depletion, and concomitant nephrotoxins.

'Hydration is not indicated in cases of hypervolemia or decompensated heart failure.

eGFR = estimated glomerular filtration rate

Figure 1. Our approach to chronic kidney disease patients requiring iodinated contrast media.

\section{Future directions}

Despite decades of research on iodinated contrast and kidney injury, many questions are yet to be answered. What is the exact mechanism of CI-AKI? What is its true incidence with intravenous vs arterial administration? What significance, if any, does CI-AKI carry?

In our aforementioned study, ${ }^{19}$ cases adjudicated to be CI-AKI carried no mortality risk, with an overall survival rate similar to that in patients who did not have acute kidney injury. Adjudication is key. We need clear definitions that capture CI-AKI clearly and distinctly from all the potential noise associated with other causes of postcontrast acute kidney injury.

The concept of "renalism" has not only led to fewer angiographic procedures being performed in the chronic kidney disease population, ${ }^{13}$ it probably also underlies the reason why patients with advanced chronic kidney disease were underrepresented in the observational cohorts described above. Studies need to target this high-risk cohort to better delineate the risks and better establish the utility, or futility, of the currently practiced prophylactic measures. Additional work is clearly needed.

\section{GADOLINIUM-INDUCED NEPHROGENIC SYSTEMIC FIBROSIS}

NSF is a debilitating and often-fatal fibrosing disease characterized by skin thickening and organ fibrosis. ${ }^{29}$ It was first reported in $15 \mathrm{di}$ alysis patients in San Diego in the year 2000.30 However, the relationship between NSF and the use of gadolinium as contrast during MRI remained obscure for a long time, finally being suggested 6 years later in Europe. ${ }^{31}$

The postulated mechanism was the deposition of toxic free gadolinium molecules in the tissues $^{32}$ with subsequent increases in circulating fibrocytes, ${ }^{33}$ an increase in the expression 


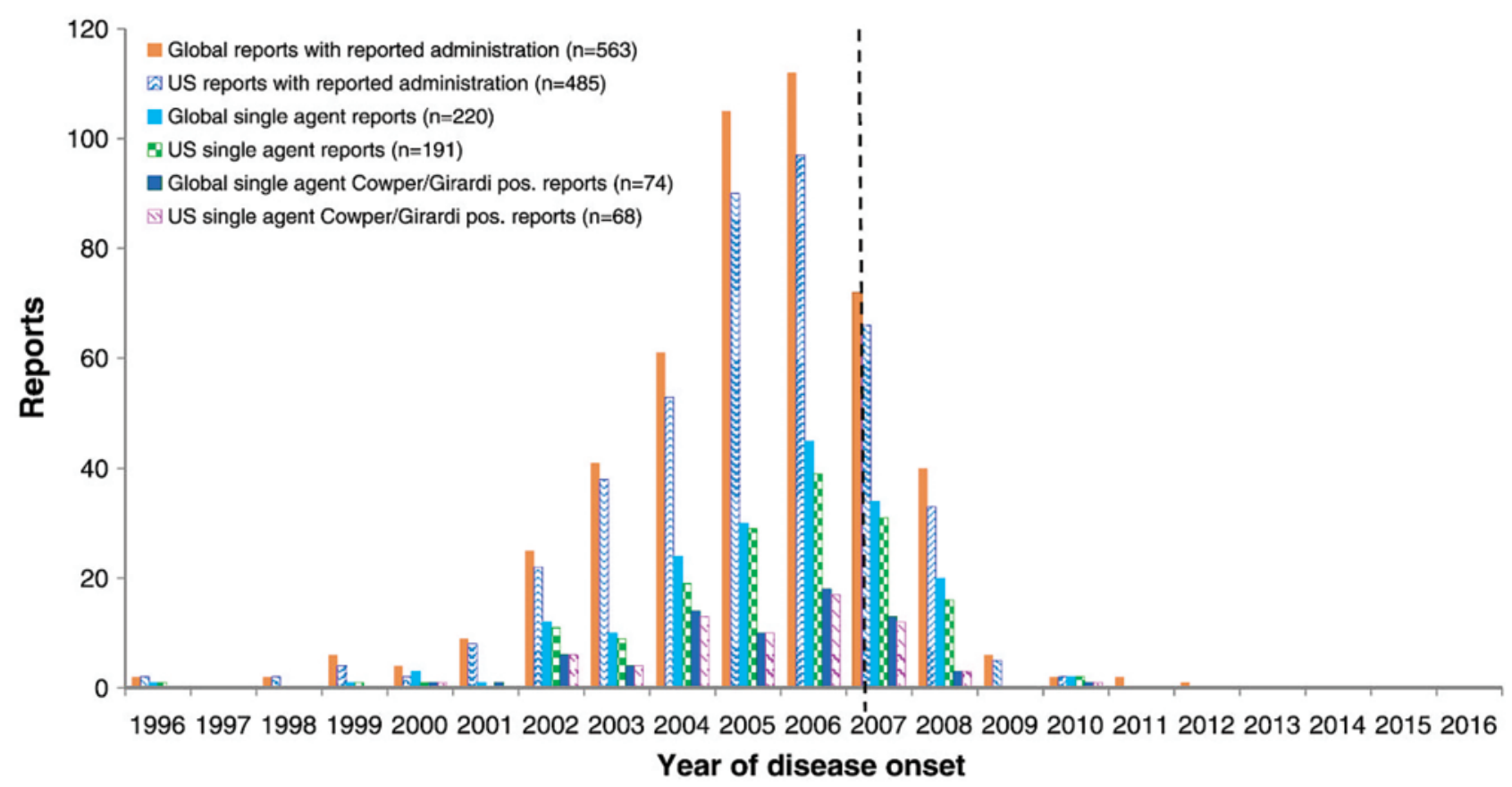

Figure 2. Number of cases of nephrogenic systemic fibrosis associated with gadopentetate dimeglumine in the United States and around with world, by year of disease onset. Vertical dotted line indicates the introduction of the boxed warning by the US Food and Drug Administration in May 2007.

Endrikat J, Dohanish S, Schleyer N, Schwenke S, Agarwal S, Balzer T. 10 Years of nephrogenic systemic fibrosis: a comprehensive analysis of nephrogenic systemic fibrosis reports received by a pharmaceutical company from 2006 to 2016 . Invest Radiol 2018; 53(9):541-550. https://journals.Iww.com/investigativeradiology/fulltext/2018/09000/10_years_of_nephrogenic_systemic_fibrosis_a.5.aspx

of transforming growth factor beta $1,,^{34}$ and release of proinflammatory and profibrotic cytokines. ${ }^{35}$ Eventually, gadolinium was detected by electron microscopy on a skin biopsy specimen, specifically in areas of calcium phosphate deposition in blood vessels. ${ }^{36}$

By 2009, the disease was well established, and the US Food and Drug Administration (FDA) had received over 500 reports, most of them from the United States ${ }^{37}$ and Denmark. ${ }^{38}$

In response to this crisis, the authorities and radiology societies were quick to react. In 2007, both the $\mathrm{FDA}^{39}$ and the European Medicine Agency ${ }^{40}$ issued warnings highlighting the risk of NSF associated with the use of gadolinium-based contrast agents. The American College of Radiology, ${ }^{41}$ European Society of Urogenital Radiology, ${ }^{42}$ and other radiology societies published guidelines and recommendations on how to use gadolinium-based contrast agents, particularly in patients with kidney disease.

Gadolinium agents that have a linear molecular shape pose a higher risk, and their use was contraindicated in patients with acute and severe chronic kidney disease with eGFRs less than $30 \mathrm{~mL} / \mathrm{min} / 1.73 \mathrm{~m}^{2}$, as well as in patients on dialysis. Additionally, evidence that gadolinium-based contrast agents are removed with dialysis ${ }^{43}$ prompted clinicians to change their clinical practice by offering dialysis to patients with advanced kidney dysfunction who were exposed to these agents.

As a result of those measures, the number of cases of NSF was drastically reduced. The last reported case in the United States dates back to 2010, and the last report in the world was in 2012 (Figure 2). ${ }^{44}$

\section{Classification of gadolinium-based contrast agents}

Gadolinium-based contrast agents have been used since the 1980s and were initially thought to have an excellent safety profile. ${ }^{45}$ This led to their liberal and preferential use compared with iodine-based agents, particularly in patients with reduced kidney function. ${ }^{46}$ However, their incriminating role in NSF highlighted their potential toxicity.

Gadolinium-based contrast agents share
Gadolinium

agents that

have a linear molecular shape pose a higher risk 


\begin{tabular}{|l|l|l|}
\hline \multicolumn{2}{|l|}{$\begin{array}{l}\text { TABLE } 3 \\
\text { Gadolinium-based contrast agents } \\
\text { and risk of nephrogenic systemic fibrosis }\end{array}$} \\
\hline \multirow{2}{*}{ Ionic } & Cyclic & Linear \\
\hline & Gadoteric acid & Gadobenate dimeglumine \\
\cline { 2 - 3 } & $\begin{array}{l}\text { Gadofosveset } \\
\text { Gadoxetic acid }\end{array}$ \\
\cline { 2 - 3 } & $\begin{array}{l}\text { Gadoteridol } \\
\text { Gadobutrol }\end{array}$ & $\begin{array}{l}\text { Gadodiamide } \\
\text { Gadoversetamide }\end{array}$ \\
\hline Nonionic & \\
\hline $\begin{array}{l}\text { Red-group I agents: associated with the greatest number of cases } \\
\text { of nephrogenic systemic fibrosis }\end{array}$ \\
\hline Green-group II agents: associated with few cases \\
\hline $\begin{array}{l}\text { Yellow-group III agents: data are limited, but few unconfirmed } \\
\text { cases have been reported }\end{array}$ \\
\hline
\end{tabular}

Several cases of NSF have been reported in patients who never were exposed to gadolinium a common structure, with a central heavy metal ion (gadolinium) bound tightly by an organic ligand to form a stable complex, thus minimizing the potential natural toxicity of the free metal ion. ${ }^{47}$ To avoid gadolinium toxicity, these agents should be highly stable so the gadolinium does not dissociate. Their stability is conferred by their chemical structure, namely whether they are linear or cyclic and whether they are charged (ionic) or electrically neutral (nonionic). ${ }^{48}$ It is generally recognized that macrocyclic and ionic structures are more stable than linear and nonionic ones. ${ }^{49}$ Thus, in highly stable agents, gadolinium dissociation is minimized and so is the risk of NSF.

On the basis of their NSF risk (and specifically on the numbers of unconfounded single-agent cases of NSF recorded for each agent), the 9 available gadolinium-based contrast agents are grouped into 3 groups $\left(\right.$ Table 3) ${ }^{41}$ :

- Group I-agents associated with the greatest number of NSF cases.

- Group II-agents associated with few, if any, unconfounded cases of NSF.

- Group III-agents for which data are limited.
It is generally accepted that groups I and III should be avoided in patients with advanced chronic kidney disease.

\section{Risk of NSF today}

The guidelines set by the FDA and the radiology societies were undoubtedly effective in curbing the disease and eventually eliminating it. A recent review of 639 patients with biopsy-proven NSF from 173 articles estimated that the risk of NSF per million exposures had decreased from 2.07 before 2008 to 0.028 afterward..$^{50}$

Most cases were associated with exposure to group I agents. However, those guidelines were applied to all gadolinium-based contrast agents without considering their stability or association with NSF. The downside of this approach was the denial of clinically indicated contrast-enhanced MRI in patients with severe kidney disease, with a subsequent potential real (though unmeasured) harm resulting from misdiagnosis or diagnostic delay. ${ }^{51}$

In recent years, evidence has been accumulating as to the safety of group II agents. A recent systematic review and meta-analysis evaluated the pooled risks of NSF in patients with stage 4 or 5 chronic kidney disease receiving a group II gadolinium-based contrast agent. ${ }^{52}$ The authors analyzed 16 studies with 4,931 patients who received group II agents. The pooled risk of NSF was 0\% (upper bound of $95 \%$ CI $0.07 \%$ ). Thus, they estimated the per-patient risk of NSF from receiving group II gadolinium-based contrast agents in stage 4 or 5 chronic kidney disease to be less than $0.07 \%$.

This risk is much smaller than that of contrast-induced nephropathy in patients with advanced chronic kidney disease who receive iodinated contrast, ${ }^{53}$ and thus argues for a better safety profile of contrast-enhanced MRI using group II agents. In fact, the risk appears to be comparable to that of developing a severe allergic reaction to contrast agents, which is estimated at $0.04 \%$ for low-osmolality iodinated contrast agents ${ }^{54}$ and $0.002 \%$ to $0.006 \%$ for group II agents. ${ }^{55}$

\section{Updated recommendations}

On the basis of accumulating evidence, ${ }^{56-60}$ the recent guidelines of the American College of Radiology, ${ }^{41}$ the European Society of Urogenital Radiology, ${ }^{61}$ and the Canadian As- 
TABLE 4

\section{Key points from the ACR Manual on Contrast Media regarding prevention of nephrogenic systemic fibrosis in patients at risk}

\begin{tabular}{|c|c|}
\hline Kidney function & Recommendation \\
\hline $\begin{array}{l}\text { Chronic kidney disease } \\
\text { stage } 1 \text { and } 2\end{array}$ & $\begin{array}{l}\text { No increased risk of developing NSF. Any } \\
\text { gadolinium-based agent can be given safely. }\end{array}$ \\
\hline $\begin{array}{l}\text { Chronic kidney disease } \\
\text { stage } 3\end{array}$ & $\begin{array}{l}\text { The risk of developing NSF is exceedingly rare. } \\
\text { No special precautions are necessary. }\end{array}$ \\
\hline $\begin{array}{l}\text { Chronic kidney disease } \\
\text { stage } 4 \text { and } 5 \\
\text { not on chronic dialysis }\end{array}$ & $\begin{array}{l}\text { Group I agents are contraindicated. If a } \\
\text { gadolinium-enhanced MRI study is to be done, } \\
\text { a group II agent should be used. }\end{array}$ \\
\hline \multirow[t]{2}{*}{$\begin{array}{l}\text { End-stage kidney disease } \\
\text { on hemodialysis }\end{array}$} & $\begin{array}{l}\text { The ACR favors CT rather than MRI if the antici- } \\
\text { pated diagnostic yield is similar. }\end{array}$ \\
\hline & $\begin{array}{l}\text { Group I agents are contraindicated. Group II } \\
\text { agents are preferred and gadolinium-enhanced } \\
\text { MRI should be performed as closely before } \\
\text { hemodialysis as is possible. }\end{array}$ \\
\hline
\end{tabular}

Authors' comments

There are no cases reported in this category with any of the gadolinium-based agents.

There have been no definite cases reported in patients with stage 3 chronic kidney disease.

Given the risk of $\mathrm{Cl}-\mathrm{AKI}$ in this population, we believe that MRI using a group II agent would be preferable to CT with iodinated contrast.

We urge caution in dialysis patients with residual kidney function, which is associated with a survival benefit. We lean toward MRI with group II agents.

Our current practice is to perform a single dialysis session rather than 2 consecutive sessions.

\begin{tabular}{ll}
\hline $\begin{array}{l}\text { End-stage kidney disease } \\
\text { on peritoneal dialysis }\end{array}$ & $\begin{array}{l}\text { The ACR favors CT when possible, but if MRI is } \\
\text { desired, then the ACR recommends a group II } \\
\text { agent. }\end{array}$
\end{tabular}

The ACR recognizes that peritoneal dialysis may provide less NSF risk reduction than hemodialysis.

\begin{abstract}
We urge caution in dialysis patients with residual kidney function, which is associated with a survival benefit. We lean toward MRI with group II agents.

The committee does not comment on the necessity of subjecting these patients to hemodialysis. We believe it is safer to perform a single session of hemodialysis, particularly for peritoneal dialysis patients with no residual kidney function.
\end{abstract}

We favor a stratified approach:

Acute kidney injury on dialysis: As in patients with end-stage kidney disease, we recommend a single session of dialysis following gadolinium exposure.

Nonoliguric acute kidney injury not on dialysis: Similar to advanced chronic kidney disease, if a gadolinium-enhanced MRI study is needed, a group II agent should be used.

Oliguric acute kidney injury not on dialysis: We favor avoiding administration of gadolinium if possible. Otherwise, our practice is to perform a single hemodialysis session.

$\mathrm{ACR}=$ American College of Radiology; $\mathrm{Cl}-\mathrm{AKI}$ = contrast-induced acute kidney injury; $\mathrm{CT}$ = computed tomography; $\mathrm{MRI}$ = magnetic resonance imaging; NSF = nephrogenic systemic fibrosis 
sociation of Radiologists ${ }^{48}$ all permit the use of group II gadolinium-based contrast agents in patients with advanced kidney disease. The American College of Radiology ${ }^{41}$ defines patients at risk of NSF as those:

- With advanced chronic kidney disease (eGFR $<30 \mathrm{~mL} / \mathrm{min} / 1.73 \mathrm{~m}^{2}$ not on dialysis)

- On dialysis (any form)

- With acute kidney injury.

In these patients, group I and III gadolinium-based contrast agents are contraindicated, with the caveat that there is insufficient reallife data to determine the risk of NSF from administration of group III agents. In patients at risk, if a gadolinium-enhanced MRI study is to be performed, a group II agent should be used. The lowest dose required to obtain the needed clinical information should be used, and it should generally not exceed the recommended single dose.

A summary of those recommendations with our comments and opinions is provided in Table $4 .{ }^{41}$

\section{Gadolinium - the end of the story?}

Although NSF has been basically eradicated since the guidelines were implemented, several cases of NSF have been reported in patients who never were exposed to gadolinium. In a review of biopsy-proven cases of NSF reported in 98 articles, 27 (8\%) of 325 patients had no clear exposure to these agents, ${ }^{62}$ and in the review of 639 biopsy-proven cases discussed above, 14 (2\%) did not. ${ }^{50}$ This suggests that gadolinium-based contrast agents are a major trigger for NSF, but they may not be the only one. Time will tell if indeed other triggers have yet to be discovered.

Additionally, in recent years, there have been data suggesting that gadolinium can deposit in the brain after repeated exposure to gadolinium-based contrast agents, even in patients with healthy kidneys. ${ }^{63}$ This finding was confirmed histologically $y^{64}$ and has led to the birth of a new term to describe it: gadolinium deposition disease. ${ }^{65}$ The significance of this brain deposition remains unknown, and to date, no adverse health effects have been uncovered. However, the FDA published a safety alert in 2015 indicating the active investigation of the risk and clinical significance of these gadolinium deposits. The recent position statement of the American College of Radiology also recognizes this phenomenon and states, "Until we fully understand the mechanisms involved and their clinical consequences, the safety and tissue deposition potential of all [gadolinium-based contrast agents] must be carefully evaluated." ${ }^{66}$

It thus appears that we haven't heard the last of gadolinium-based contrast agent-related disease. Additional research will be needed to understand the potential consequences of the use of these agents.

\section{REFERENCES}

1. Bartels ED, Brun GC, Gammeltoft A, Gjørup PA. Acute anuria following intravenous pyelography in a patient with myelomatosis. Acta Med Scand 1954; 150(4):297-302. doi:10.1111/j.0954-6820.1954.tb18632.x

2. Parfrey PS, Griffiths SM, Barrett BJ, et al. Contrast material-induced renal failure in patients with diabetes mellitus, renal insufficiency, or both. A prospective controlled study. N Engl J Med 1989; 320(3):143-149. doi:10.1056/NEJM198901193200303

3. Hou SH, Bushinsky DA, Wish JB, Cohen JJ, Harrington JT. Hospitalacquired renal insufficiency: a prospective study. Am J Med 1983; 74(2):243-248. doi:10.1016/0002-9343(83)90618-6

4. McCullough PA, Adam A, Becker CR, et al. Epidemiology and prognostic implications of contrast-induced nephropathy. Am J Cardiol 2006; 98(6A):5K-13K. doi:10.1016/j.amjcard.2006.01.019

5. Khwaja A. KDIGO clinical practice guidelines for acute kidney injury. Nephron Clin Pract 2012; 120(4):c179-c184. doi:10.1159/000339789

6. McCullough PA, Adam A, Becker CR, et al. Risk prediction of contrast-induced nephropathy. Am J Cardiol 2006; 98(6A):27K-36K. doi:10.1016/j.amjcard.2006.01.022

7. Stratta P, Bozzola C, Quaglia M. Pitfall in nephrology: contrast nephropathy has to be differentiated from renal damage due to atheroembolic disease. J Nephrol 2012; 25(3):282-289. doi:10.5301/jn.5000093

8. Devireddy C, Hiremath S. Acute kidney injury after transcatheter aortic valve replacement. Circ Cardiovasc Interv 2018; 11(8):e007135 doi:10.1161/CIRCINTERVENTIONS.118.007135

9. Andò G, Gragnano F, Calabrò P, Valgimigli M. Radial vs femoral access for the prevention of acute kidney injury (AKI) after coronary angiography or intervention: a systematic review and meta-analysis. Catheter Cardiovasc Interv 2018; 92(7):E518-E526. doi:10.1002/ccd.27903

10. Mehran R, Dangas GD, Weisbord SD. Contrast-associated acute kidney injury. N Engl J Med 2019; 380(22):2146-2155. doi:10.1056/NEJMra1805256

11. McDonald RJ, McDonald JS, Bida JP, et al. Intravenous contrast material-induced nephropathy: causal or coincident phenomenon? Radiology 2013; 267(1):106-118. doi:10.1148/radiol.12121823

12. Chertow GM, Normand SLT, McNeil BJ. "Renalism": inappropriately low rates of coronary angiography in elderly individuals with renal insufficiency. J Am Soc Nephrol 2004; 15(9):2462-2468. doi:10.1097/01.ASN.0000135969.33773.0B

13. Davenport MS, Khalatbari S, Cohan RH, Dillman JR, Myles JD, Ellis JH. Contrast material-induced nephrotoxicity and intravenous lowosmolality iodinated contrast material: risk stratification by using estimated glomerular filtration rate. Radiology 2013; 268(3):719728. doi:10.1148/radiol.13122276

14. McDonald JS, McDonald RJ, Carter RE, Katzberg RW, Kallmes DF, Williamson EE. Risk of intravenous contrast material-mediated acute kidney injury: a propensity score-matched study stratified 
by baseline-estimated glomerular filtration rate. Radiology 2014; 271(1):65-73. doi:10.1148/radiol.13130775

15. Hinson JS, Ehmann MR, Fine DM, et al. Risk of acute kidney injury after intravenous contrast media administration. Ann Emerg Med 2017; 69(5):577-586.e4. doi:10.1016/j.annemergmed.2016.11.021

16. Hiremath S, Velez JCQ. Preventing a nonexistent entity: the curious case of contrast and acute kidney injury. Curr Opin Nephrol Hypertens 2020; 29(1):152-160. doi:10.1097/MNH.0000000000000562

17. Rudnick MR, Leonberg-Yoo AK, Litt HI, Cohen RM, Hilton S, Reese PP. The controversy of contrast-induced nephropathy with intravenous contrast: what Is the risk? Am J Kidney Dis 2020; 75(1):105-113. doi:10.1053/j.ajkd.2019.05.022

18. Ghumman SS, Weinerman J, Khan A, et al. Contrast induced-acute kidney injury following peripheral angiography with carbon dioxide versus iodinated contrast media: a meta-analysis and systematic review of current literature. Catheter Cardiovasc Interv 2017; 90(3):437-448. doi:10.1002/ccd.27051

19. Chaudhury P, Armanyous S, Harb SC, et al. Intra-arterial versus intravenous contrast and renal injury in chronic kidney disease: a propensity-matched analysis. Nephron 2019; 141(1):31-40. doi:10.1159/000494047

20. Solomon R, Werner C, Mann D, D'elia J, Silva P. Effects of saline mannitol, and furosemide on acute decreases in renal function induced by radiocontrast agents. N Engl J Med 1994; 331(21):14161420. doi:10.1056/NEJM199411243312104

21. Mueller C, Buerkle G, Buettner HJ, et al. Prevention of contrast media-associated nephropathy: randomized comparison of 2 hydration regimens in 1620 patients undergoing coronary angioplasty. Arch Intern Med 2002; 162(3):329-336. doi:10.1001/archinte.162.3.329

22. Nijssen EC, Rennenberg RJ, Nelemans PJ, et al. Prophylactic hydration to protect renal function from intravascular iodinated contrast material in patients at high risk of contrast-induced nephropathy (AMACING): a prospective, randomised, phase 3 , controlled, openlabel, non-inferiority trial. Lancet 2017; 389(10076):1312-1322. doi:10.1016/S0140-6736(17)30057-0

23. Timal RJ, Kooiman J, Sijpkens YWJ, et al. Effect of no prehydration vs sodium bicarbonate prehydration prior to contrast-enhanced computed tomography in the prevention of postcontrast acute kidney injury in adults with chronic kidney disease: the Kompas randomized clinical trial. JAMA Intern Med 2020; 180(4):533-541. doi:10.1001/jamainternmed.2019.7428

24. Weisbord SD, Gallagher M, Jneid H, et al. Outcomes after angiography with sodium bicarbonate and acetylcysteine. N Engl J Med 2018; 378(7):603-614. doi:10.1056/NEJMoa1710933

25. Berwanger $\boldsymbol{O}$. Acetylcysteine for prevention of renal outcomes in patients undergoing coronary and peripheral vascular angiography: main results from the randomized Acetylcysteine for Contrast-induced nephropathy Trial (ACT). Circulation 2011; 124(11):1250-1259. doi:10.1161/CIRCULATIONAHA.111.038943

26. Bargman JM, Thorpe KE, Churchill DN. Relative contribution of residual renal function and peritoneal clearance to adequacy of dialysis: a reanalysis of the CANUSA study. J Am Soc Nephrol 2001; (10):2158-2162. pmid:11562415

27. Shemin D, Bostom AG, Laliberty P, Dworkin LD. Residual renal function and mortality risk in hemodialysis patients. Am J Kidney Dis 2001; 38(1):85-90. doi:10.1053/ajkd.2001.25198

28. Davenport MS, Perazella MA, Yee J, et al. Use of intravenous iodinated contrast media in patients with kidney disease: consensus statements from the American College of Radiology and the National Kidney Foundation. Radiology 2020; 294(3):660-668. doi:10.1148/radiol.2019192094

29. Cowper SE, Bucala R, Leboit PE. Nephrogenic fibrosing dermopathy/ nephrogenic systemic fibrosis—setting the record straight. Semin Arthritis Rheum 2006; 35(4):208-210. doi:10.1016/j.semarthrit.2005.09.005

30. Cowper SE, Robin HS, Steinberg SM, Su LD, Gupta S, LeBoit PE. Scleromyxoedema-like cutaneous diseases in renal-dialysis patients. Lancet 2000; 356(9234):1000-1001. doi:10.1016/S0140-6736(00)02694-5
31. Grobner T. Gadolinium - a specific trigger for the development of nephrogenic fibrosing dermopathy and nephrogenic systemic fibrosis? Nephrol Dial Transplant 2006; 21(4):1104-1108. doi:10.1093/ndt/gfk062

32. Marckmann P, Skov L, Rossen K, et al. Nephrogenic systemic fibrosis: suspected causative role of gadodiamide used for contrastenhanced magnetic resonance imaging. J Am Soc Nephrol 2006; 17(9):2359-2362. doi:10.1681/ASN.2006060601

33. Mendoza FA, Artlett CM, Sandorfi N, Latinis K, Piera-Velazquez S, Jimenez SA. Description of 12 cases of nephrogenic fibrosing dermopathy and review of the literature. Semin Arthritis Rheum 2006; 35(4):238-249. doi:10.1016/j.semarthrit.2005.08.002

34. Jiménez SA, Artlett CM, Sandorfi N, et al. Dialysis-associated systemic fibrosis (nephrogenic fibrosing dermopathy): study of inflammatory cells and transforming growth factor B1 expression in affected skin. Arthritis Rheum 2004; 50(8):2660-2666. doi:10.1002/art.20362

35. Wermuth PJ, Del Galdo F, Jiménez SA. Induction of the expression of profibrotic cytokines and growth factors in normal human peripheral blood monocytes by gadolinium contrast agents. Arthritis Rheum 2009; 60(5):1508-1518. doi:10.1002/art.24471

36. Boyd AS, Zic JA, Abraham JL. Gadolinium deposition in nephrogenic fibrosing dermopathy. J Am Acad Dermatol 2007; 56(1):27-30. doi:10.1016/j.jaad.2006.10.048.

37. Thomsen HS. Nephrogenic systemic fibrosis: history and epidemiology. Radiol Clin North Am 2009; 47(5):827-831, vi. doi:10.1016/j.rcl.2009.05.003

38. Stenver DI. Pharmacovigilance: what to do if you see an adverse reaction and the consequences. Eur J Radiol 2008; 66(2):184-186. doi:10.1016/j.ejrad.2008.02.009

39. US Food and Drug Administration. FDA warns that gadoliniumbased contrast agents (GBCAs) are retained in the body; requires new class warnings. Accessed September 10, 2020. https://www.fda. gov/media/109825/download

40. European Medicines Agency. Assessment report for gadolinium-containing contrast agents. Accessed September 10, 2020. https://www. ema.europa.eu/en/documents/referral/gadolinium-h-31-1097-assessment-report_en.pdf

41. ACR Committee on Drugs and Contrast Media. ACR Manual on Contrast Media. American College of Radiology: 2020. Accessed September 10, 2020. https://www.acr.org///media/ACR/Files/ClinicalResources/Contrast_Media.pdf

42. Thomsen HS, Morcos SK, Almén T, et al. Nephrogenic systemic fibrosis and gadolinium-based contrast media: updated ESUR Contrast Medium Safety Committee guidelines. Eur Radiol 2013; 23(2):307218. doi:10.1007/s00330-012-2597-9

43. Okada S, Katagiri K, Kumazaki T, Yokoyama H. Safety of gadolinium contrast agent in hemodialysis patients. Acta Radiol 2001; 42(3):339-341. pmid:11350296

44. Endrikat J, Dohanish S, Schleyer N, Schwenke S, Agarwal S, Balzer T. 10 Years of nephrogenic systemic fibrosis: a comprehensive analysis of nephrogenic systemic fibrosis reports received by a pharmaceutical company from 2006 to 2016. Invest Radiol 2018; 53(9):541-550. doi:10.1097/RLI.0000000000000462

45. Niendorf HP, Dinger JC, Haustein J, Cornelius I, Alhassan A, Clauß W. Tolerance data of Gd-DTPA: a review. Eur J Radiol 1991; 13(1):1520. doi:10.1016/0720-048x(91)90049-2

46. Hammer FD, Goffette PP, Malaise J, Mathurin P. Gadolinium dimeglumine: an alternative contrast agent for digital subtraction angiography. Eur Radiol 1999; 9(1):128-136. doi:10.1007/s003300050643.

47. Gibby WA, Gibby KA, Gibby WA. Comparison of Gd DTPA-BMA (Omniscan) versus Gd HP-DO3A (ProHance) retention in human bone tissue by inductively coupled plasma atomic emission spectroscopy. Invest Radiol 2004; 39(3):138-142. doi:10.1097/01.rli.0000112789.57341.01

48. Schieda N, Blaichman Jl, Costa AF, et al. Gadolinium-based contrast agents in kidney disease: comprehensive review and clinical practice guideline issued by the Canadian Association of Radiologists. Can Assoc Radiol J 2018; 69(2):136-150. doi:10.1016/j.carj.2017.11.002 
49. Hao D, Ai T, Goerner F, Hu X, Runge VM, Tweedle M. MRI contrast agents: basic chemistry and safety. J Magn Reson Imaging 2012; 36(5):1060-1071. doi:10.1002/jmri.23725

50. Attari H, Cao Y, Elmholdt TR, Zhao Y, Prince MR. A systematic review of 639 patients with biopsy-confirmed nephrogenic systemic fibrosis. Radiology 2019; 292(2):376-386. doi:10.1148/radiol.2019182916

51. Balogh EP, Miller BT, Ball JR, eds. Improving Diagnosis in Health Care. Washington, DC: National Academies Press, 2016.

52. Woolen SA, Shankar PR, Gagnier JJ, MacEachern MP, Singer L, Davenport MS. Risk of nephrogenic systemic fibrosis in patients with stage 4 or 5 chronic kidney disease receiving a group II gadoliniumbased contrast agent: a systematic review and meta-analysis. JAMA Intern Med 2020; 180(2):223-230. doi:10.1001/jamainternmed.2019.5284

53. Davenport MS, Cohan RH, Ellis JH. Contrast media controversies in 2015: imaging patients with renal impairment or risk of contrast reaction. Am J Roentgenol 2015; 204(6):1174-1181. doi:10.2214/AJR.14.14259

54. Katayama H, Yamaguchi K, Kozuka T, Takashima T, Seez P, Matsuura $\mathrm{K}$. Adverse reactions to ionic and nonionic contrast media. a report from the Japanese Committee on the Safety of Contrast Media. Radiology 1990; 175(3):621-628. doi:10.1148/radiology.175.3.2343107

55. Behzadi AH, Zhao Y, Farooq Z, Prince MR. Immediate allergic reactions to gadolinium-based contrast agents: a systematic review and meta-analysis. Radiology 2018; 286(2):471-482 doi:10.1148/radiol.2017162740

56. Michaely HJ, Aschauer M, Deutschmann H, et al. Gadobutrol in renally impaired patients: results of the GRIP study. Invest Radiol 2017; 52(1):55-60. doi:10.1097/RLI.0000000000000307

57. Soyer P, Dohan A, Patkar D, Gottschalk A. Observational study on the safety profile of gadoterate meglumine in 35,499 patients: the SECURE study. J Magn Reson Imaging 2017; 45(4):988-997. doi:10.1002/jmri.25486

58. Tsushima Y, Awai K, Shinoda G, et al. Post-marketing surveillance of gadobutrol for contrast-enhanced magnetic resonance imaging in Japan. Jpn J Radiol 2018; 36(11):676-685. doi: 10.1007/s11604-018-0778-4
59. Young LK, Matthew SZ, Houston JG. Absence of potential gadolinium toxicity symptoms following 22,897 gadoteric acid (Dotarem ${ }^{\circledR}$ ) examinations, including 3,209 performed on renally insufficient individuals. Eur Radiol 2019; 29(4):1922-1930. doi:10.1007/s00330-018-5737-z

60. Bruce R, Wentland AL, Haemel AK, et al. Incidence of nephrogenic systemic fibrosis using gadobenate dimeglumine in 1423 patients with renal insufficiency compared with gadodiamide. Invest Radiol 2016; 51(11):701-705. doi:10.1097/RLI.0000000000000259

61. European Society of Urogenital Radiology. ESUR on contrast media. Accessed September 2020. http://www.esur.org/guidelines/

62. Zou Z, Zhang HL, Roditi GH, Leiner T, Kucharczyk W, Prince MR. Nephrogenic systemic fibrosis: review of 370 biopsy-confirmed cases. JACC: Cardiovasc Imaging 2011; 4(11):1206-1216. doi:10.1016/j.jcmg.2011.08.013

63. Kanda T, Ishii K, Kawaguchi H, Kitajima K, Takenaka D. High signal intensity in the dentate nucleus and globus pallidus on unenhanced T1-weighted MR images: relationship with increasing cumulative dose of a gadolinium-based contrast material. Radiology 2014; 270(3):834-841. doi:10.1148/radiol.13131669

64. Kanda T, Fukusato T, Matsuda M, et al. Gadolinium-based contrast agent accumulates in the brain even in subjects without severe renal dysfunction: evaluation of autopsy brain specimens with inductively coupled plasma mass spectroscopy. Radiology 2015; 276(1):228-232. doi:10.1148/radiol.2015142690

65. Semelka RC, Ramalho J, Vakharia A, et al. Gadolinium deposition disease: initial description of a disease that has been around for a while. Magn Reson Imaging 2016; 34(10):1383-1390. doi:10.1016/j.mri.2016.07.016

66. ACR-ASNR position statement on the use of gadolinium contrast agents. Created May 2016. Accessed September 29, 2020. https:// icpme.us/2016ACR/ACR_ASNR_Position_Statement_on_the_Use_of_ Gadolinium_Contrast_Agents.pdf

Address: Ali Mehdi, MD, Department of Nephrology and Hypertension, Q7, Cleveland Clinic, 9500 Euclid Avenue, Cleveland, OH 44195; mehdia@ccf.org 